\title{
Custos do ciclo de vida dos estabelecimentos assistenciais de saúde (EAS) e suas implicações para o Sistema Único de Saúde - SUS
}

\author{
Ewerton Mendes ROSA(1) \\ Leonardo CARNUT $^{(1)}$ \\ ${ }^{(1)}$ Faculdade de Saúde Pública, Universidade de São Paulo - USP, São Paulo, SP, Brasil.
}

Recebido: 28 jan 2019 Aceito: 10 fev 2019

Autor de correspondência: ton_ewtn@hotmail.com Conflito de interesses: Os autores declaram não haver nenhum interesse profissional ou pessoal que possa gerar conflito de interesses em relação a este manuscrito.

\section{Resumo}

Diferentemente da área da saúde, na qual o conceito de ciclo de vida remete aos organismos vivos, na construção civil o mesmo está associado às diversas fases relacionadas a uma edificação, com os respectivos aspectos do empreendimento, permitindo analisá-los ao longo do tempo, avaliar o desempenho e quantificar impactos e custos. O conceito está cada vez mais presente devido as suas implicações para o desenvolvimento sustentável. Por sua vez, o Custo do Ciclo de Vida - CCV refere-se ao custo total de propriedade ao longo de toda a vida de um bem. Tipicamente, os centros de custos inclusos referem-se ao planejamento, projetos, aquisição de terra, construção, operação, manutenção, renovações, recuperações, depreciação, custo financeiro do capital e descarte. A estrutura física dos estabelecimentos assistenciais de saúde (EAS) é de grande importância para suporte das atividades desenvolvidas. Praticamente todas ações em saúde estão vinculadas a fluxos a serem desenvolvidos e a requisitos mínimos a serem atendidos com o objetivo de proporcionar condições operacionais de pessoas e equipamentos e minimizar riscos sanitários. Cabe ressaltar que os EAS são, em última instância, espaços de produção de subjetividades no âmbito do trabalho em saúde. Os processos sociais de organização do trabalho para uma melhor atenção à saúde perpassam pela adequação da estrutura física ao processo que nele se encerra, configurando-se assim, a ambiência do espaço de trabalho como um elemento crucial na humanização da prestação da atenção. Por estas razões, a arquitetura pode e deve ser uma ferramenta facilitadora de mudança no processo de trabalho. A partir dessas considerações, a qualificação dos investimentos nos EAS deve ir além da abordagem restrita ao custo da construção, perpassando, dentre outros fatores, a adequação e qualidade do ambiente construído e a avaliação do CCV da edificação, englobando as diversas fases envolvidas e considerando as interferências e impactos das decisões desde a sua concepção e planejamento. Além de comprometer o desempenho, aspectos não considerados ou sanados em etapas iniciais acarretam custos crescentes para a manutenção e operação do edifício, fase que demanda maior volume de recursos, de forma que aparentes economias na implantação de um EAS podem acarretar maiores custos posteriores, gerando ineficiência na aplicação desses, além de maiores impactos ambientais e sociais. Quanto ao Sistema Único de Saúde - SUS, algumas evidências demonstram que a estrutura 
física dos serviços é um dos elementos que mais apresenta fragilidades. Dados sistematizados demonstram que, na visão do usuário da Atenção Básica, essa é a dimensão mais mal avaliada. Objetivo: considerando a problemática do subfinanciamento do SUS e a necessidade de melhor aplicação dos escassos recursos no longo prazo através da qualificação do investimento, o estudo tem como objetivo levantar o estado do conhecimento relativo ao tema, revisando o que a literatura tem produzido nas últimas décadas, levantando as discussões pertinentes, referenciais de boas práticas, indicadores utilizados e programas governamentais, com objetivo de avançar na temática da eficiência na alocação de recursos nos EAS ao longo do seu ciclo de vida. Complementarmente, é oportuna a identificação das lacunas existentes e aspectos que requeiram maior aprofundamento. Método: a pesquisa é uma revisão integrativa da literatura utilizando-se da busca sistematizada na plataforma da BIREME por estudos que abordam ou tangenciam o tema, delimitando-se critérios para inclusão dos resultados. A definição de descritores foi realizada a partir do questionamento da pesquisa - O que a literatura científica apresenta sobre os custos do ciclo de vida dos estabelecimentos assistenciais de saúde (EAS)? - agrupando descritores e palavras-chave em quatro polos: (a) custos; (b) ciclo de vida; (c) estabelecimento assistencial de saúde (EAS); e (d) SUS. Ao introduzir o descritor do sistema único de saúde, constatou-se a inexistência de resultados, indicando uma possível lacuna na abordagem do tema na saúde pública do Brasil. Ressalva-se que assistematicamente foram encontradas publicações do Ministério da Saúde relativas ao tema e outros trabalhos locais com estudos de caso em determinado EAS. Por conta disso, a pesquisa utiliza os descritores dos outros três polos citados derivados da pergunta inicial, possibilitando a inserção da discussão referente ao SUS na avaliação dos resultados, sem comprometer a metodologia da revisão. Resultados: a sintaxe final é: (tw:((mh:((mh:("conservacao dos recursos naturais")) $O R$ (mh:("conservacao de recursos energeticos")) $O R$ (mh:("consumo de energia")) $O R$ (mh:("energia renovavel")) $O R$ (mh:("ar condicionado")) $O R$ (mh:("conservacao dos recursos naturais")) $O R$ (mh:("indicadores de desenvolvimento sustentavel")) )) $O R$ (tw:("ciclo de vida")) $O R$ (tw:("life-cycle")) $O R$ (tw:("life cycle")))) AND (mh:((mh:("Analise de Custo em Saude")) $O R$ (mh:("investimentos em saude")) $O R$ (mh:("gastos em saude")) $O R$ (mh:("financiamento de construcoes")) $O R$ (mh:("Custos e Analise de Custo")) $O R$ (mh:("organização do financiamento")) $O R$ (mh:("gastos de capital")) $O R$ (mh:("financiamento de capital")) $O R$ (mh:("financiamento de capital")) $O R$ (mh:("custos hospitalares")) $O R$ (mh:("reducao de custos")) $O R$ (mh:("economia hospitalar")) )) $A N D$ (mh:((mh:("arquitetura hospitalar")) $O R$ (mh:("arquitetura de instituicoes de saude")) $O R$ (mh:("arquitetura")) $O R$ (mh:("construcao de instituicoes de saude")) $O R$ (mh:("edificios")) $O R$ (mh:("construcao")) $O R$ (mh:("Tamanho das Instituicoes de Saude")) $O R$ (mh:("instalacoes de saude")) )). Foram obtidos 63 resultados, todos estrangeiros. Considerações finais: nota-se, a partir de uma análise preliminar, que o tema não possui relevância em pesquisas nacionais em economia e gestão em saúde. Além dos materiais do Ministério da 
Saúde, as referências relacionadas ao assunto estão principalmente nas áreas da arquitetura e engenharia civil, obtidas em buscas assistematizadas nas bases de bibliotecas específicas. Ao considerarmos o subfinanciamento do Sistema Único de Saúde, bem como a necessidade de maior eficiência alocativa dos recursos financeiros, torna-se oportuno ampliar essa temática nas discussões, face sua importância e impacto. A partir das constatações, e uma vez identificada a lacuna na área de conhecimento, tomou-se como alternativa a realização de uma revisão integrativa, combinando estudos obtidos na busca descrita e outros dados da literatura empírica. O trabalho encontra-se na fase de revisão por pares dos resultados obtidos na busca sistematizada, aplicando-se como critérios de exclusão a verificação quanto ao pertencimento à temática e de haver resposta à pergunta de pesquisa.

Descritores: Custos e Análise de Custo; Investimentos em Saúde; Economia Hospitalar; Arquitetura Hospitalar; Arquitetura de Instituições de Saúde. 